\title{
Ergosterol, arabitol and mannitol as tracers for biogenic aerosols in the eastern Mediterranean
}

\author{
N. Burshtein, N. Lang-Yona, and Y. Rudich \\ Department of Environmental Sciences and Energy Research, The Weizmann Institute of Science, Rehovot 76100, Israel \\ Received: 13 September 2010 - Published in Atmos. Chem. Phys. Discuss.: 12 November 2010 \\ Revised: 11 January 2011 - Accepted: 16 January 2011 - Published: 31 January 2011
}

\begin{abstract}
Aerosols containing biological components can have a significant effect on human health by causing primarily irritation, infection and allergies. Specifically, airborne fungi can cause a wide array of adverse responses in humans depending on the type and quantity present. In this study we used chemical biomarkers for analyzing fungi-containing aerosols in the eastern Mediterranean region during the year 2009 in order to quantify annual fungal abundances. The prime marker for fungi used in this study was ergosterol, and its concentrations were compared with those of mannitol and arabitol which were recently suggested to also correlate with fungal spores concentrations (Bauer et al., 2008a). Back trajectory analysis, inorganic ions, humidity and temperature were used in an attempt to identify sources as well as the dependence on seasonal and environmental conditions. We found that the ambient concentrations of ergosterol, arabitol and mannitol range between 0 and $2.73 \mathrm{ng} \mathrm{m}^{-3}, 1.85$ and $58.27 \mathrm{ng} \mathrm{m}^{-3}, 5.57$ and $138.03 \mathrm{ng} \mathrm{m}^{-3}$, respectively. The highest levels for all biomarkers were during the autumn, probably from local terrestrial sources, as deduced from the inorganic ions and back trajectory analysis. Significant correlations were observed between arabitol and mannitol during the entire year except for the winter months. Both sugars correlated with ergosterol only during the spring and autumn. We conclude that mannitol and arabitol might not be specific biomarkers for fungi and that the observed correlations during spring and autumn may be attributed to high levels of vegetation during spring blossoms and autumn decomposing.
\end{abstract}

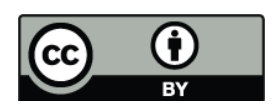

Correspondence to: Y. Rudich (yinon.rudich@weizmann.ac.il)

\section{Introduction}

Airborne particles that originate from living organisms, plants, cell parts, pollen, bacteria and fungal spores are termed bioaerosols. Uplifting of biological particles to the atmosphere is possible when mechanical disturbances such as dust storms, activated sludge systems and irrigation with reclaimed water occur (Crook et al., 1997; Schlesinger et al., 2006; Taha et al., 2006). Bioaerosols have been implicated in many environmental processes such as modification of clouds by serving as cloud and ice condensation nuclei (Hoose, 2009; Kurup et al., 2000; Kurup, 2003; Möhler et al., 2007; Vali et al., 1996) as well as affecting human health by causing primarily irritation, infection and allergies (PeiChih et al., 2000; Shelton et al., 2002).

Measurements of aerosol phospholipids content suggest that pollen and fungal spores contribute 4 to $11 \%$ of the total mass in particulate matter less than $2.5 \mu \mathrm{m}$ in aerodynamic diameter $\left(\mathrm{PM}_{2.5}\right)$ or 12 to $22 \%$ of the total organic carbon fraction of ambient aerosols (Womiloju et al., 2003). More recent estimations suggest that fungal spores account for about $60 \%$ of the coarse atmospheric organic carbon, and for $40 \pm 5 \%$ of the coarse PM mass as was measured in Vienna during spring and summer 2005 (Bauer et al., 2008b).

Fungi are important microorganisms in nature for they decompose most of the organic material. The vast majority of fungi have terrestrial habitats, in soil or dead plant matter (Madigan et al., 1997). Most fungi emit spores that range between 1.5 and $12 \mu \mathrm{m}$ (Cox and Wathes, 1995; Ruzer and Harley, 2005). These spores constitute a significant portion of the natural bioaerosols. These particles have long retention time in the atmosphere and can travel long distances.

Fungal spores can penetrate into the human airways and irritate the respiratory system, cause allergies and infectious acute diseases such as alvioletis and upper airway blockage as well as chronic disease such as asthma and bronchitis

Published by Copernicus Publications on behalf of the European Geosciences Union. 
(Douwes et al., 2003; Fung and Hughson, 2003; Kurup et al., 2000; Kurup, 2003; Ring, 2001; Ruzer and Harley, 2005). Emissions of volatile organic compounds from microorganisms such as fungi can also cause human health problems such as irritation of mucous membranes and damage to the central nerve system (Fung and Hughson, 2003; Ruzer and Harley, 2005). Glucose polymers in the cell walls of most fungi such as (1-3)- $\beta$-D-glucans can induce inflammatory responses and cause respiratory symptoms (Douwes et al., 2003; Shelton et al., 2002).

The adverse responses to fungi depend on their type and quantity. Since dose response is highly individual, the sensitivity of an exposed person is an important consideration (Ruzer and Harley, 2005). The abundance of bioaerosols in the ambient air and their health impacts depend on the season and on the environmental conditions. For example, the release of spores and their allergenic effects depend on water content (Ruzer and Harley, 2005).

Estimating the concentration of fungi in the atmosphere is commonly conducted using viable samplers or spore traps. With viable samplers it is possible to enumerate only live species, while spore traps followed by microscopic examination can provide total spore counts regardless of their viability. Both approaches provide number concentrations and species identification, but they are labor-intensive and time consuming. They do not provide the contribution of fungal spores to atmospheric aerosols in terms of mass loading or impacts (Lau et al., 2006). To quantify and identify fungi contribution to atmospheric aerosols and the impact to public health, it has been suggested to use biomarkers in chemical analysis of collected aerosols. An often used biomarker for determining the fungal biomass is ergosterol (Lau et al., 2006), which is a primary fungal membrane sterol shown in Fig. 1a. Ergosterol is almost exclusively found in fungi and is therefore an efficient biomarker. Photochemical degradation can cause a significant decrease of ergosterol content in living fungi, therefore it is necessary to avoid light exposure once the fungi are collected (Mille-Lindblom et al., 2004). Gas Chromatography-Mass Spectrometry (GCMS) is the most efficient mean for determination ergosterol (Miller and Young, 1997). Trimethylsilyl derivatization of ergosterol is often used for increasing the detection sensitivity. The derivatization occurs by replacing the hydrogen from the OH group by a trimethylsilyl group (Saraf et al., 1997).

Recently, Bauer et al. (2008a) suggested that mannitol and arabitol (Fig. 1b, c) concentrations are correlated with the fungal spore counts in atmospheric $\mathrm{PM}_{10}$ (mass of airborne particles that have an aerodynamic diameter smaller then $10 \mu \mathrm{m})$ (Bauer et al., 2008a). This finding was confirmed by Zhang et al. (2010) who measured arabitol and mannitol during April and May 2004 in southern China. These sugar alcohols (polyols) are common storage substances in fungal spores. Bauer et al. suggest that using these polyols for spores simplifies sampling, analytical analysis and evades the need for parallel aerosol collection. Mannitol, although

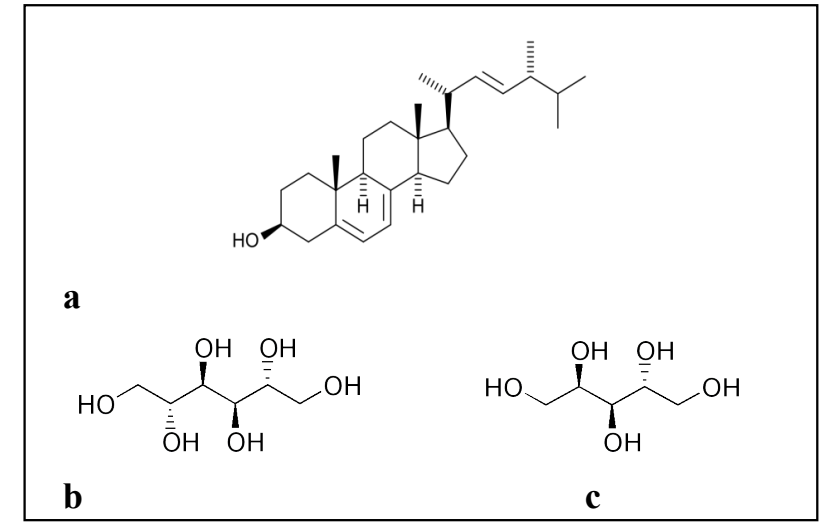

Fig. 1. Molecular structures of Ergosterol (a) Mannitol (b) and arabitol (c).

common in fungi, is also a common sugar alcohol in plants; it is particularly abundant in algae and has been detected in at least 70 higher plant families. This suggests that mannitol may not be a specific biomarker for fungi as ergosterol (Loescher et al., 1992).

Inorganic cations $\left(\mathrm{Na}^{+}, \mathrm{NH}_{4}^{+}, \mathrm{K}^{+}, \mathrm{Mg}^{2+}, \mathrm{Ca}^{2+}\right)$ and anions $\left(\mathrm{Cl}^{-}, \mathrm{NO}_{3}^{-}, \mathrm{SO}_{4}^{2-}\right)$ are common markers for identifying aerosol sources and processes. Inorganic ions can often provide important information about the origin of the aerosols and are often used for source identification (Hays et al., 2002).

To date, limited research on the abundance and sources of biogenic aerosols in the Mediterranean basin in general and in Israel in particular has been conducted. While there is pioneering research on bioaerosols occurrence in this region (Schlesinger et al., 2006; Waisel et al., 2008), the biomarkers approach has not been applied yet. Fungi biomarkers in aerosols have not yet been studied and therefore the seasonal fungi abundance and the potential health effects, apart from dust storms (Schlesinger et al., 2006), are not well known.

In this study, ergosterol, arabitol, mannitol and inorganic ions were quantified in ambient aerosols in the Eastern Mediterranean region. Several goals were set:

1. Quantify ergosterol concentrations in ambient $\mathbf{P M}_{10}$ aerosol in order to study the annual and seasonal behavior of fungi-containing bioaerosols.

2. Test whether arabitol and mannitol are good predictors of ergosterol and hence of fungal containing aerosols.

3. Explore correlations between the tracers' abundance with inorganic ions, humidity, temperature, and synoptic data in order to identify dominant sources of fungal spores. 


\section{Experimental methods}

\subsection{Sample collection}

Samples were collected using a high volume sampler (Ecotech High volume sampler model ECO-HVS3000 with $\mathrm{PM}_{10}$ inlet, rate of drawing $68 \mathrm{~m}^{3} \mathrm{~h}^{-1}$ ) on the roof of a building at the Weizmann Institute of Science, Rehovot, Israel $\left(31^{\circ} 54^{\prime} 27^{\prime \prime} \mathrm{N}, 34^{\circ} 48^{\prime} 33^{\prime \prime} \mathrm{E}\right)$. About sixty samples were collected on a semi weekly basis, between December 2008 and December 2009, each sampling was for $72 \mathrm{~h}$. Quartz microfiber filters (Whatman $20.3 \times 25.4 \mathrm{~cm}$ ) were used. They were prebaked prior to use at $450^{\circ} \mathrm{C}$ for $5 \mathrm{~h}$ in order to burn off organic matter that might contaminate the samples. All samples were kept at $-20^{\circ} \mathrm{C}$ from collection until analysis in order to inhibit fungal growth.

\subsection{Analytical procedure}

\subsubsection{Ergosterol}

Dark tubes and vials were used to avoid photochemical degradation, and the sampled filters were wrapped in aluminum foil. 1/8 of each filter was hydrolyzed in glass tubes containing methanol (Merck, >99.9\%) and placed in an ultrasonic bath containing $50^{\circ} \mathrm{C}$ water for $45 \mathrm{~min}$ to break the fungi cell walls and release ergosterol to the solvent. Ergosterol extraction was performed twice using de-ionized water and hexane (Sigma-Aldrich 97.0\%). 100ng of an internal standard, 7-Dehydro cholesterol (DHC) (Sigma, >98.0\%), was added to each sample in order to estimate sample stability. DHC is a stable internal standard with a chemical structure very similar to that of ergosterol. Division of the ergosterol peak area by the DHC peak area gave the relative response factor (RRF) which expresses the real amount of ergosterol and takes into account possible variations in sample preparation and extraction.

The excess water and hexane were evaporated under a gentle stream of nitrogen. The samples were re-dissolved in hexane-dichloromethane solution (1:1 v/v) (Sigma-Aldrich, 99.8\%) and were applied to disposable silica gel columns (Phenomenex $100 \mathrm{mg} / 1.5 \mathrm{ml} 100 \mathrm{pk}$ ) pre-conditioned with hexane:dichloromethane $(1: 1 \mathrm{v} / \mathrm{v})$ mixture that decreased the analysis error by filtering unwanted components present in the sample. Extraction was performed with $2 \mathrm{ml}$ hexane:dichloromethane mixture $(1: 1 \mathrm{v} / \mathrm{v})$ followed by $2 \mathrm{ml}$ ethyl acetate (Sigma-Aldrich, 99.9\%), the samples were again evaporated under a stream of nitrogen. Ergosterol and DHC derivatization was performed using Bis (Trimethylsilyl) trifluoro-acetamid (BSTFA) (Aldrich, 99.0+). Pyridine (Aldrich 99.8\%) was used as a catalyst. Derivatization improves the ergosterol signal to noise ratio (Lau et al., 2006; Saraf et al., 1997). After reacting at $65^{\circ} \mathrm{C}$ for 45 minutes the samples were injected to a Varian GC-MS Saturn 2000 equipped with a Restek column ( $\mathrm{RXi}-5 \mathrm{~ms}$. 5\% diphenyl
95\% dimethyl polysiloxane. $30 \mathrm{~m}, 0.25 \mathrm{~mm} \mathrm{ID}, 0.25 \mu \mathrm{m})$. A sensitive GC-MS/MS procedure was developed for obtaining a high sensitivity. The second MS stage was used to detect the ergosterol at $363 \mathrm{~m} / \mathrm{z}$ and DHC at $351 \mathrm{~m} / \mathrm{z}$. Injector split ratio was adjusted to the splitless mode to enhance sensitivity. Column flow rate was constant at 1.4 PSI except from a pressure pulse at 40 PSI for the first minute. Ergosterol retention time was between 25.6 to $26.1 \mathrm{~min}$. Calibration curve is presented in Fig. 2.

\subsubsection{Mannitol and arabitol}

Mannitol and arabitol were detected and quantified by ion chromatography using the following procedure: the sampled filter was weighted and for each sample, a $3 \mathrm{~cm}^{2}$ piece was weighed separately. All samples were analyzed in duplicates. $6 \mathrm{ml}$ of de-ionized water were added to each sample and put in an ultrasonic bath for $45 \mathrm{~min}$ at room temperature. The samples were filtrated in $0.45 \mu \mathrm{m}$ syringe filter (Acrodisk) and were injected to the Ion Chromatograph (Dionex) with a CarboPac column (Dionex, MA1; $4 \times 250 \mathrm{~mm} \&$ guard). The column temperature was set to $30^{\circ} \mathrm{C}$, eluent flow $(\mathrm{NaOH})$ was set to a rate of $0.4 \mathrm{ml} \mathrm{s}^{-1}$ and the injection volume was $50 \mu \mathrm{l}$. The detector was an electrochemical detector with a gold electrode as a work electrode and silver-chloride as reference electrode (Dionex). Arabitol (Sigma, >98.0\%) and mannitol (Riedel de Haen, extra pure) were used as standards. Calibration curve is presented in Fig. 2.

\subsubsection{Inorganic ions}

A $3 \mathrm{~cm}^{2}$ piece of the filter was used for each analysis; all samples were analyzed in duplicates. $8 \mathrm{ml}$ of de-ionized water were added to each sample. The samples were put in an ultra sonic bath for $45 \mathrm{~min}$ at room temperature; they were then filtrated with a $0.45 \mu \mathrm{m}$ syringe filter (Acrodisc) and injected to an Ion Chromatograph (Dionex) All laboratory glassware was washed carefully with de-ionized water prior to use.

Anions were detected using the following conditions: the flow rate of mobile phase, $\mathrm{NaOH} 13 \mathrm{mM}$ was $1 \mathrm{ml} \mathrm{min}^{-1}$ with injection volume of $50 \mu \mathrm{l}$ and suppressor current of $40 \mathrm{~mA}$. An IonPac column (AS11A $4 \times 250 \mathrm{~mm} \&$ guard IonPac AG11A $4 \times 50 \mathrm{~mm}$ ) was used, were the column temperature was set to $25^{\circ} \mathrm{C}$. A suppressor (ASRS $3004 \mathrm{~mm}$ self regeneration), a conductivity detector (Dionex) and an automated autosampler (Dionex) were utilized.

Cations were detected using the following conditions: flow rate of mobile phase, Methanesulfonic Acid $20 \mathrm{mM}$ (Fluka) was $1.2 \mathrm{ml} \mathrm{min}^{-1}$ with injection volume of $50 \mu \mathrm{l}$ and suppressor current of $59 \mathrm{~mA}$. An IonPac column (CS12A $4 \times 250 \mathrm{~mm} \&$ guard IonPac CG12A $4 \times 50 \mathrm{~mm}$ ) was used and the column temperature was set to $30^{\circ} \mathrm{C}$. A suppressor (CSRS $3004 \mathrm{~mm}$ self regeneration), a conductivity detector (Dionex) and an automated autosampler (Dionex) 


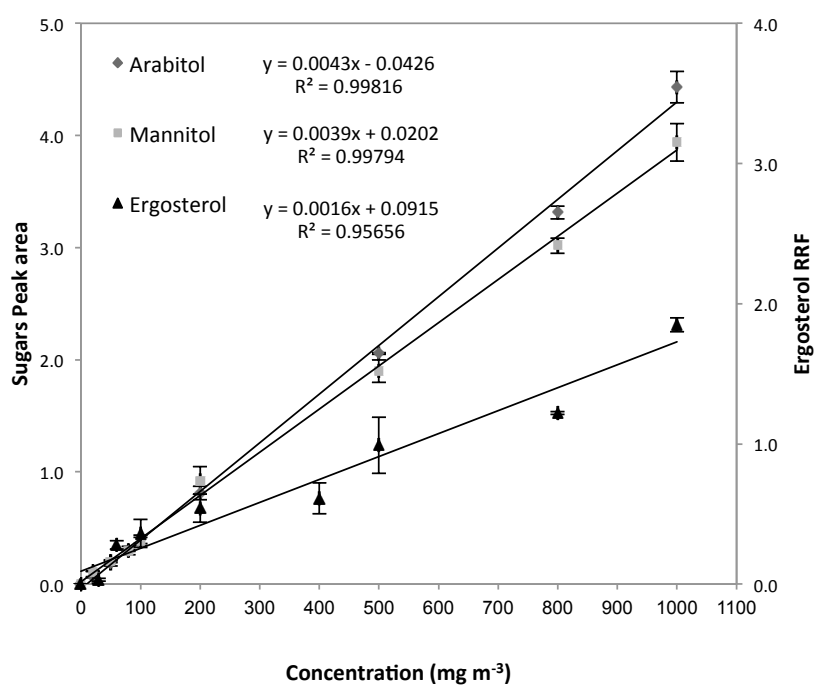

Fig. 2. Calibration curves for arabitol, mannitol and ergosterol.

were utilized. Calibration curves with $r^{2}>99 \%$ were prepared according to the protocol above with: Ammonium Nitrate (Sigma Aldrich); Magnesium Sulfate (Baker); Calcium Chloride (Baker); Sodium Chloride (Fluka); Potassium Chloride (Merck); Ammonium Sulfate (Fluka); Sodium Nitrate (Riedel de haein). The following anions and cations were quantified: $\mathrm{Cl}^{-}, \mathrm{NO}_{3}^{-}, \mathrm{SO}_{4}^{2-}, \mathrm{Na}^{+}, \mathrm{NH}_{4}^{+}, \mathrm{K}^{+}, \mathrm{Mg}^{2+}$ and $\mathrm{Ca}^{2+}$.

\subsection{Meteorological information}

Humidity and temperature data was obtained from the meteorology station at the Hebrew University in Rehovot and the meteorological station in Nes-ziona on a daily basis. Recorded dust storms events were taken from the ministry of environmental protection.

\subsection{Back trajectory analysis}

Back trajectories were calculated for each sampled filter using the Hybrid Single Particle Lagrangian Integrated Trajectory Model (HYSPLIT) (Draxler and Rolph, 2010) developed by the United States National Oceanic and Atmospheric Administration (NOAA). The model produced back trajectories for 3 days for the sampling dates at 3 different heights $(500,1000,1500 \mathrm{~m})$ providing estimate of the source direction for each sample separately with the model vertical velocity, coordinates of the Weizmann institute are $31^{\circ} 54^{\prime} 27^{\circ} \mathrm{N}$ and $34^{\circ} 48^{\prime} 33^{\circ} \mathrm{E}$. The HYSPLIT model was commonly used in different occasions to estimate $\mathrm{PM}_{10}$ sources (Dayan and Levi, 2005; Escudero et al., 2006; Falkovich et al., 2001; Waisel et al., 2008).

\section{Results and discussion}

\subsection{Calibration curves for ergosterol, arabitol and mannitol}

The analytical tools used in this study were all verified and calibrated with standards in concentration ranges relevant for the samples. Ergosterol, arabitol and mannitol were detected with good precision, calibration curves for are shown in Fig. 2. For ergosterol each peak area was divided by the DHC peak area giving a relative response factor (RRF). An internal standard was not needed for mannitol and arabitol, because they are stable species.

\subsection{Ergosterol, arabitol and mannitol concentrations during 2009}

In Figs. 3 and 4, the variation of ergosterol, mannitol and arabitol in our sampling site from December 2008 to December 2009 are shown. The gaps in the data were caused by technical issues. The data covers $46 \%$ of the year. Table 1 provides detailed concentrations. The data contains 14 winter samples (December, January, February), 8 spring samples (March, April, May), 17 summer samples (June, July, August) and 17 autumn samples (September, October, November) totaling 56 samples. The ambient concentrations of ergosterol, arabitol and mannitol range between 0 and $2.73 \mathrm{ng} \mathrm{m}^{-3}, 1.85$ and $58.27 \mathrm{ng} \mathrm{m}^{-3}, 5.57$ and $138.03 \mathrm{ng} \mathrm{m}^{-3}$, respectively. A visible correlation is noticeable between arabitol and mannitol during this year; the highest levels for all biomarkers are seen in the autumn when the vegetation decomposes and fungal population increase.

The concentrations of the three biomarkers were in the same order of magnitude and range to those reported for Hong Kong and Vienna. Ergosterol concentrations in Hong Kong were between 30.7 to $407.3 \mathrm{pg} \mathrm{m}^{-3}$ (Lau et al., 2006), sugars levels in Vienna during the autumn months were between 7 and $63 \mathrm{ng} \mathrm{m}^{-3}$, and between 8.9 and $83 \mathrm{ng} \mathrm{m}^{-3}$ for arabitol and mannitol respectively (Bauer et al., 2008a). The slight difference in the biomarkers' concentrations between Israel, Hong Kong and Austria may be attributed to the difference in the types of fungi species collected, the climatic regions and amount of surrounding vegetation.

\subsection{Seasonal correlations between the biomarkers}

Table 2 details the Pearson correlation coefficient $(r)$ between mannitol and arabitol during the different seasons. Apart from the winter months, arabitol and mannitol are highly correlated throughout the year. Ergosterol is highly correlated with arabitol and moderately correlated with mannitol during spring and autumn but shows no correlation with both sugars during summer and winter.

Ergosterol is an established biomarker for fungi (Gessner and Schmitt, 1996; Lau et al., 2006; Lee et al., 2007; Mille-Lindblom et al., 2004; Miller and Young, 1997; Saraf 
Table 1. Biomarkers levels were detected in each of the sampling dates $\left(\mathrm{ng} \mathrm{m}^{-3}\right)$. Each date shown represents the starting date of the sampling period during $72 \mathrm{~h}$. Averages are shown for each biomarker in all seasons. Arabitol, mannitol and ergosterol show the highest average concentrations during the autumn season, the lowest levels are seen during summer for ergosterol and mannitol and during winter for arabitol.

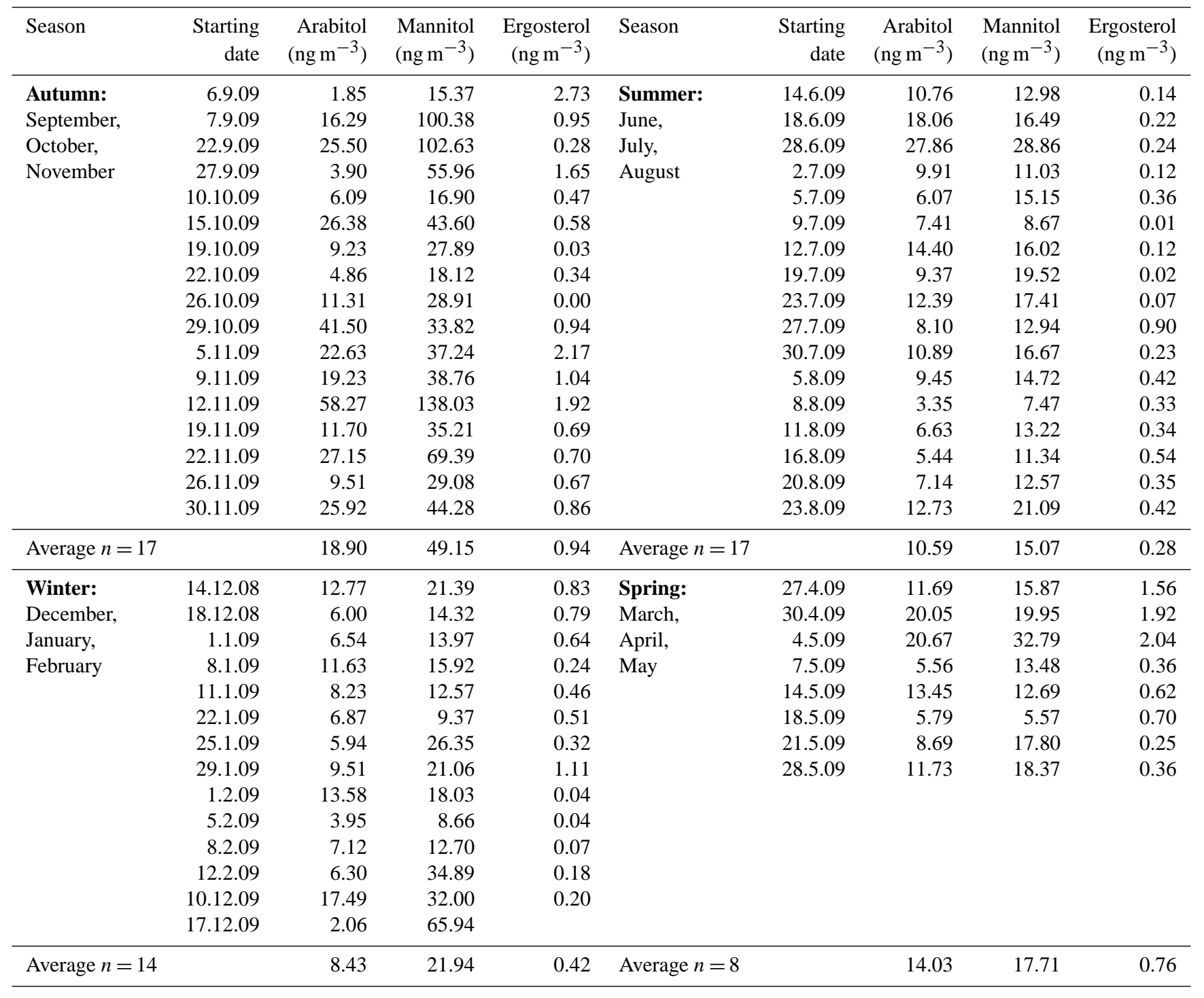

et al., 1997). According to Lau (2006) highest ergosterol levels were observed in Hong Kong during the autumn months (September, October, November and December) as was observed in Israel. Although slightly different in climate, it can be seen that in both regions the fungal spores have similar behavior.

Although Bauer et al. suggestion that arabitol and mannitol can serve as fungi markers, with the advantage of the easier detection and quantification (Bauer et al., 2008a), our data show that in our region, these sugars correlate with ergosterol during spring and autumn but not during winter and summer. Bauer's measurements were conducted only during the autumn, when high concentrations of the sugars were observed in both sites and a significant correlation was found between them and the fungal spores (Bauer et al., 2008a). Although there are differences in environmental conditions between Israel and Austria, the arabitol levels detected were usually lower than mannitol levels in Israel, similarly to the observations in Austria.

Mannitol and arabitol, although common in fungi, are most frequently occurring sugar alcohol in plants; mannitol is particularly abundant in algae and has been detected in at least 70 higher plant families (Cheng et al., 2009; Lafay-Ette et al., 2004; Loescher et al., 1992). Hence, we conclude that 
Table 2. Pearson coefficient $(r)$ was used in order to determine the correlation between the markers during each season. Arabitol and mannitol are highly correlated during the year apart from the winter season. Ergosterol shows moderate correlation with both arabitol and mannitol during spring and autumn.

\begin{tabular}{lrrr}
\hline & $\begin{array}{r}\text { Arabitol vs. } \\
\text { mannitol }\end{array}$ & $\begin{array}{r}\text { Mannitol vs. } \\
\text { ergosterol }\end{array}$ & $\begin{array}{r}\text { Arabitol vs. } \\
\text { ergosterol }\end{array}$ \\
\hline Winter & -0.18 & -0.06 & -0.03 \\
Spring & $\underline{\mathbf{0 . 7 8}}$ & $\mathbf{0 . 6 0}$ & $\underline{\mathbf{0 . 8 1}}$ \\
Summer & $\underline{\mathbf{0 . 8 3}}$ & -0.11 & -0.24 \\
Autumn & $\mathbf{0 . 6 6}$ & $\mathbf{0 . 4 1}$ & $\mathbf{0 . 6 6}$ \\
\hline
\end{tabular}

$\pm \mathbf{0 . 7 0 - 1 . 0 0}$ - high correlation

$\pm \mathbf{0 . 5 0}-\mathbf{0 . 7 0}$ - moderate correlation

$\pm 0.30-0.50$ - low correlation.

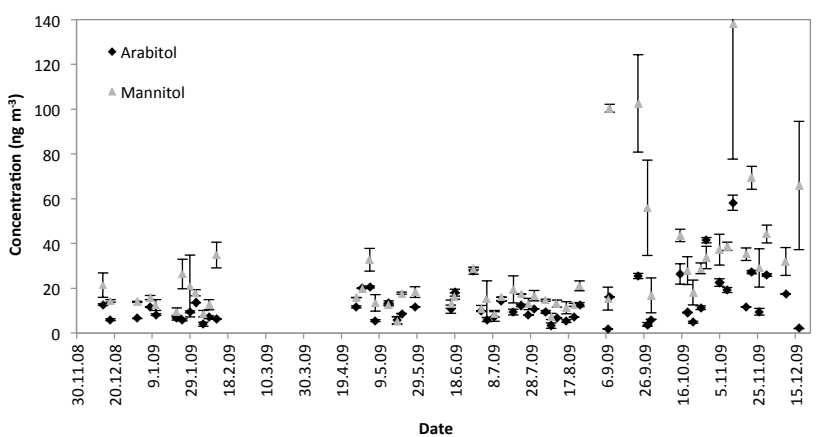

Fig. 3. Arabitol and mannitol concentrations during 2009. Missing samples are due to technical failures of the high volume sampler. High concentrations of the biomarkers are seen during the autumn.

mannitol and arabitol are not specific biomarkers for fungi. The observed correlation is confusing and might be attributed to high levels of vegetation during spring blossoms and autumn decomposing and not necessarily have a direct relation with fungi levels. Therefore we suggest that further studies should be conducted in order to establish whether they are good predictors of fungal spores.

\subsection{Effects of ambient conditions on biomarkers concentration}

We have investigated the correlation between the temperature and relative humidity (at the sampling point) and the biomarkers. Figures 5-6 show the correlation of concentration with relative humidity and temperature. The highest ergosterol concentrations were observed when the relative humidity was below $58 \%$ and between $18-21^{\circ} \mathrm{C}$. At higher temperatures and $\mathrm{RH}$, ergosterol concentrations decrease. During the measurements, average relative humidity in our site was between 55 and 70\% (Fig. 6). Lau (2006) reported that the highest ergosterol levels were detected when the RH was below 75\% (Lau et al., 2006). For Vienna the

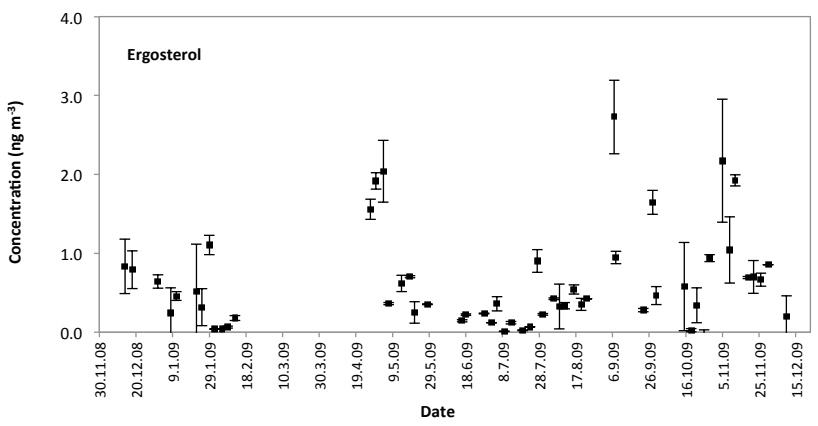

Fig. 4. Ergosterol concentration during 2009. High concentrations are seen during the autumn.

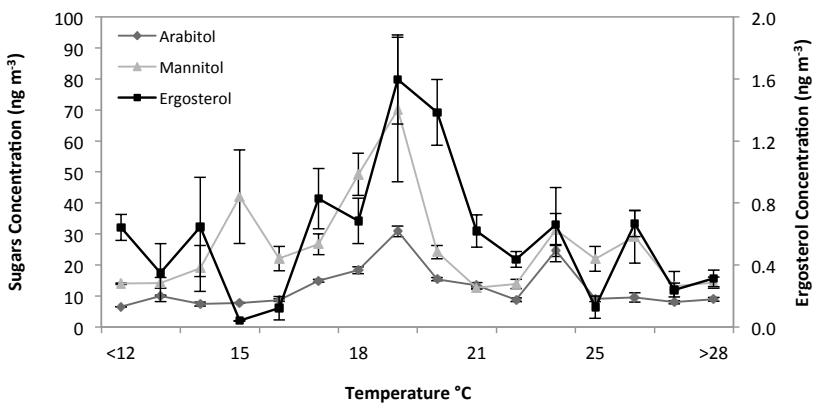

Fig. 5. Correlation between ambient ergosterol, arabitol and mannitol levels and temperature at the sampling site. The maximum values of all biomarkers appear between $19-20^{\circ} \mathrm{C}$ which are typical average temperatures for the spring and autumn seasons.

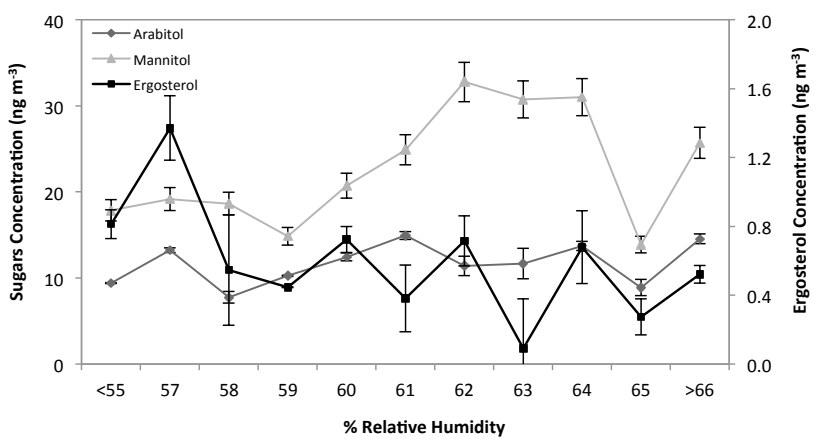

Fig. 6. Correlation between the ambient ergosterol, arabitol and mannitol concentrations with average relative humidity at the sampling site. Ergosterol shows high levels at low \% RH while mannitol levels rise when average \%RH between $62-65 \%$. Arabitol does not show a distinct relationship with the relative humidity.

relative humidity was not reported. Arabitol and mannitol show high levels between $18-21^{\circ} \mathrm{C}$, as ergosterol does. Relative humidity levels did not show significant influence on arabitol, while mannitol levels are the highest when the RH is between $62-64 \%$. The different influence of the relative humidity on the biomarkers can be another indication for the different sources of each of them. 
Table 3. Pearson correlation coefficient $(r)$ between $\mathrm{Ca}^{2+}$ levels and the measured biomarkers as was calculated for 8 dust events sampled during 2009. Low correlation is observed suggesting that the biomarkers are from a local source.

\begin{tabular}{rrrr}
\hline & Arabitol & Mannitol & Ergosterol \\
\hline $\mathrm{Ca}^{2+}$ levels during dust events & 0.34 & 0.36 & 0.07 \\
\hline
\end{tabular}

Humidity was previously found to be a significant factor in effecting fungi concentrations. It was found that fungi are more abundant when the humidity is high in both indoor and outdoor environments (Arundel et al., 1986; Cox and Wathes, 1995; Elbert et al., 2007; Li and LaMondia, 2010). However, ergosterol was negatively correlated with relative humidity in Hong Kong (Lee et al., 2007), our results show the same trend, meaning that high humidity levels do not have a straight relation with high biomarker concentrations. This could be explained by the facts that the source of the spores is from air mass from inland where the humidity is relatively low when compared to the humidity when the air mass arrives from the Mediterranean Sea. We estimate that this explains the observed negative correlation with the humidity, since the sea may be a weaker source of spores.

\subsection{Biomarkers concentrations by geographical sectors}

$72 \mathrm{~h}$ back trajectories were calculated for each sample using HYSPLIT model (Draxler and Rolph, 2010). The back trajectory model ran for $72 \mathrm{~h}$ back for each sampling date in order to capture the $72 \mathrm{~h}$ time frame of the sampling. In a research conducted recently in Maryland, the transport and characterization of ambient biological aerosol were studied using the back trajectories model. They found that the backtrajectory analysis indicate that samples that originated from both the ocean and land mass, were consistent with genetic material found in the samples, which show evidence of both soil and oceanic origins (Santarpia et al., 2010).

The trajectories were broadly separated into 4 sectors (Dayan and Levi, 2005), each sector was categorized according to the major synoptic scenarios common in Israel: southern Europe \& Mediterranean Sea, Turkey \& central western Asia, Arabian Peninsula and North Africa \& Sahara (Fig. 7). Typical trajectories for each of the sections are shown in Fig. 8.

We found that the higher concentrations of mannitol and arabitol are associated with terrestrial trajectories or by mixed trajectories - trajectories that contain both terrestrial and marine sources (Fig. 9), while ergosterol has the highest concentrations only when the trajectories are from terrestrial source (Fig. 10). Ergosterol has the higher levels when originating from terrestrial sources also in Hong Kong (Lee et al., 2007).

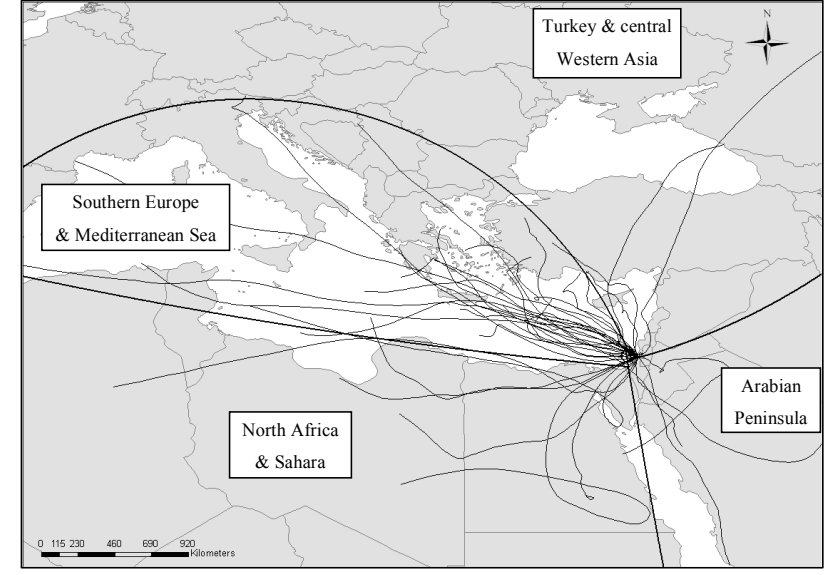

Fig. 7. Distribution of the trajectories according to air directions typical to Israel region. The trajectories are separated into 4 sectors (Dayan and Levi, 2005) that were categorized according to the main air directions common in the area. The major sources are: southern Europe \& Mediterranean Sea, Turkey \& central western Asia, Arabian Peninsula and North Africa \& Sahara.

When investigating the trajectories according to sectors and seasons division (Fig. 11), generally, all biomarkers have the highest values when arriving from North Africa - Sahara region and Turkey. Mannitol and ergosterol show high levels when coming from the Turkey region mainly during autumn. The same qualitative conclusions are obtained when investigating 24 or $48 \mathrm{~h}$ trajectories.

\subsection{Statistical analysis for biomarkers and inorganic ions}

The Pearson $\chi^{2}$ test was chosen for its simplicity in explaining the relations between several inorganic ions and biomarkers coordinated with seasonality. Since we were interested in examining the correlations separately for each season and we only have several samples from each season (between 8 and 17), the most suitable statistical analysis was the Pearson test. When we applied a principle component analysis (PCA) we could not observe any significant correlations, probably due to lack of measurements. The disadvantage of the Pearson test is that we could not identify any patterns that hide within the data but we were able to reveal the most significant correlations.

During 8 dust storm events that were sampled during 2009 we observed higher than average $\mathrm{Ca}^{2+}$ levels, as was previously reported (Falkovich et al., 2001; Schlesinger et al., 2006). The biomarkers levels (Table 4), in those dusty sampling days had very low correlation with the $\mathrm{Ca}^{2+}$ levels measured (Table 3 ). The correlations suggest that the average concentrations of biomarkers are low at most dust events, suggesting that ergosterol and hence fungi concentrations are not related to dust storms events. This finding may indicate 
Table 4. Inorganic ions and their correlation with the biomarkers were examined. Pearson coefficient $(r)$ was used in order to determine the correlation between the measured biomarkers and the inorganic ions during each season. Arabitol (1), Mannitol (2), Ergosterol (3).

\begin{tabular}{lrrrrrrrrrrrr}
\hline Season & & Winter & \multicolumn{4}{c}{ Spring } & \multicolumn{3}{c}{ Summer } & \multicolumn{3}{c}{ Autumn } \\
& 1 & 2 & 3 & 1 & 2 & 3 & 1 & 2 & 3 & 1 & 2 & 3 \\
\hline $\mathrm{Cl}^{-}$ & -0.01 & -0.09 & -0.04 & $\mathbf{0 . 7 6}$ & $\underline{\mathbf{0 . 8 2}}$ & $\underline{\mathbf{0 . 7 9}}$ & $\mathbf{0 . 3 3}$ & 0.20 & -0.15 & $\mathbf{0 . 3 4}$ & 0.24 & 0.12 \\
$\mathrm{NO}_{3}^{-}$ & $\mathbf{0 . 5 8}$ & 0.00 & -0.14 & -0.22 & $-\mathbf{0 . 3 3}$ & $-\mathbf{0 . 4 8}$ & 0.02 & 0.08 & -0.22 & 0.05 & $-\mathbf{0 . 3 1}$ & 0.12 \\
$\mathrm{SO}_{4}^{2-}$ & 0.23 & $-\mathbf{0 . 5 1}$ & 0.10 & $-\mathbf{0 . 5 6}$ & $-\mathbf{0 . 4 7}$ & $-\mathbf{0 . 7 1}$ & $-\mathbf{0 . 5 5}$ & $-\mathbf{0 . 3 9}$ & 0.05 & -0.04 & -0.13 & -0.05 \\
$\mathrm{Na}^{+}$ & 0.08 & -0.22 & -0.11 & $\mathbf{0 . 4 2}$ & $\mathbf{0 . 5 8}$ & $\underline{\mathbf{0 . 7 1}}$ & 0.10 & 0.02 & $-\mathbf{0 . 3 2}$ & $\mathbf{0 . 4 8}$ & -0.25 & 0.13 \\
$\mathrm{NH}_{4}^{+}$ & $\mathbf{0 . 3 7}$ & $-\mathbf{0 . 3 3}$ & 0.10 & $-\mathbf{0 . 5 0}$ & $\mathbf{- 0 . 5 0}$ & $\underline{\mathbf{- 0 . 7 6}}$ & $-\mathbf{0 . 4 5}$ & $-\mathbf{0 . 4 0}$ & 0.02 & -0.07 & -0.07 & 0.21 \\
$\mathrm{~K}^{+}$ & 0.07 & $-\mathbf{0 . 3 7}$ & 0.21 & $\mathbf{0 . 5 0}$ & 0.15 & $\mathbf{0 . 5 4}$ & -0.24 & 0.00 & $\mathbf{0 . 6 5}$ & 0.27 & 0.19 & -0.05 \\
$\mathrm{Mg}^{2+}$ & 0.10 & -0.27 & -0.18 & $\mathbf{0 . 4 9}$ & $\mathbf{0 . 6 8}$ & $\underline{\mathbf{0 . 7 2}}$ & $-\mathbf{0 . 4 4}$ & -0.12 & 0.06 & $\mathbf{0 . 3 0}$ & -0.15 & 0.12 \\
$\mathrm{Ca}^{2+}$ & 0.01 & $-\mathbf{0 . 3 8}$ & $-\mathbf{0 . 3 1}$ & 0.11 & -0.10 & 0.18 & -0.03 & 0.15 & $\mathbf{0 . 4 1}$ & -0.01 & 0.24 & 0.12 \\
\hline
\end{tabular}

$\pm \mathbf{0 . 7 0 - 1 . 0 0}$ - high correlation

$\pm \mathbf{0 . 5 0 - 0 . 7 0}$ - moderate correlation

$\pm 0.30-0.50$ - low correlation
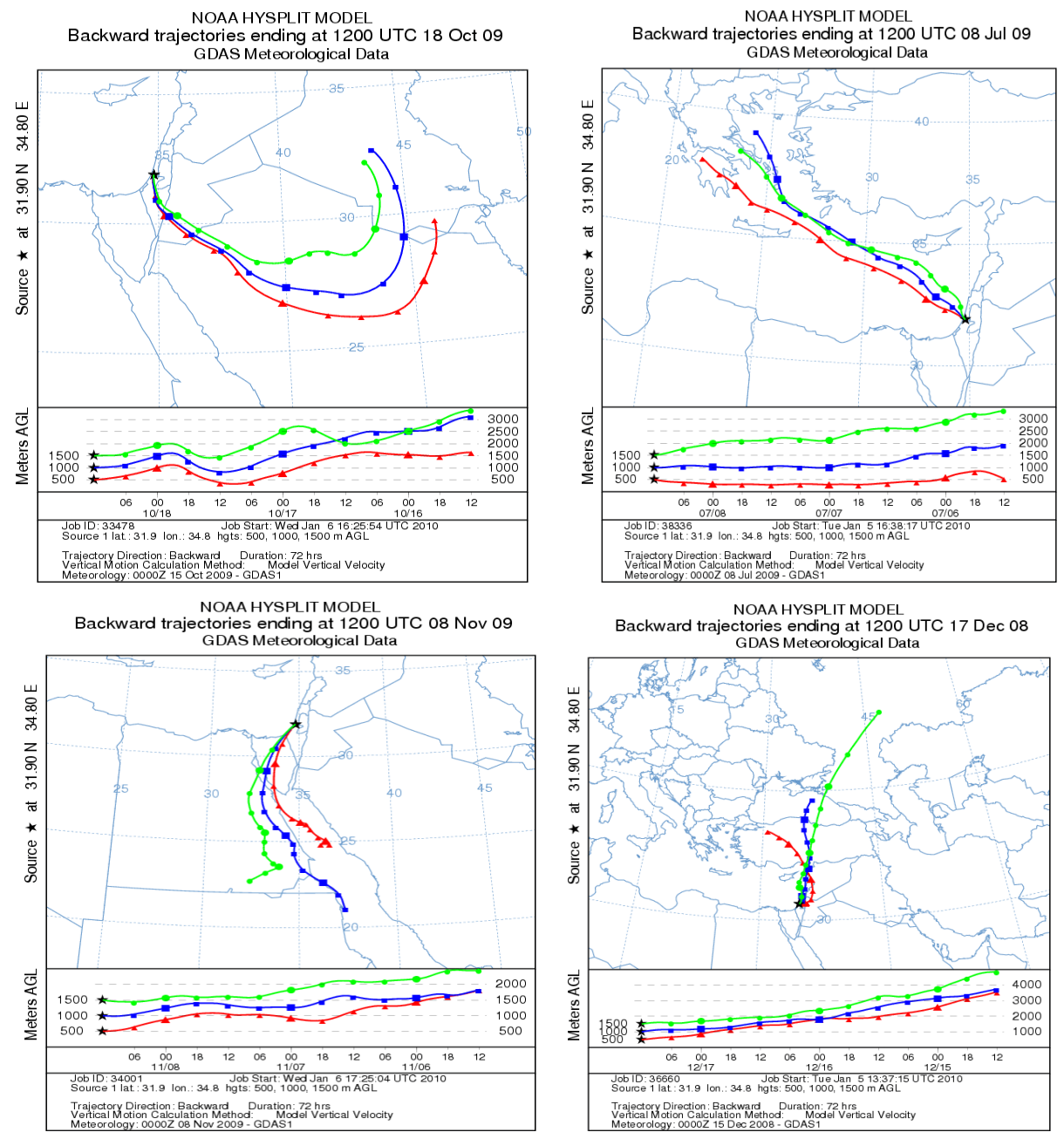

Fig. 8. Typical trajectories found for each sample with clockwise direction: Arabian peninsula, southern Europe \& Mediterranean Sea, North Africa \& Sahara and Turkey \& Central Western Asia. In most cases the trajectories obtained in the different heights were similar to each other. In cases at which trajectories at the different heights deviated from each other, the trajectory plotted at the average height of $1000 \mathrm{~m}$ was used to classify the sample to the sectors shown in Fig. 7. 


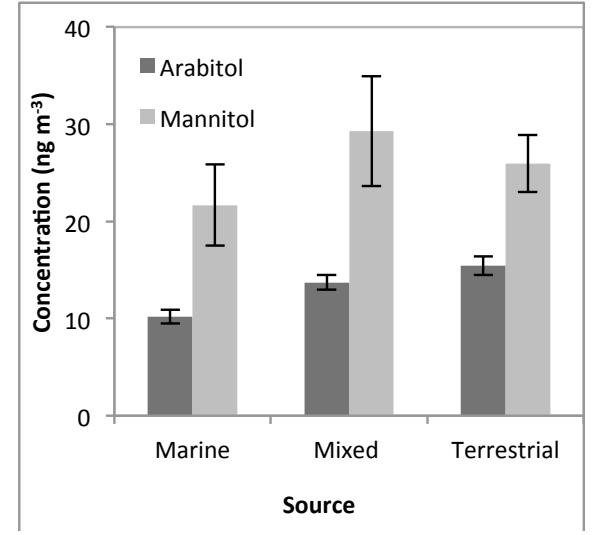

Fig. 9. Arabitol and mannitol concentrations according to source, broadly characterized to: marine environment (air mass that originated from the Mediterranean Sea), terrestrial sources (air mass from inland environments) and mixed sources (air mass that are not classified as marine or terrestrial). Arabitol has the highest concentrations when the samples are from terrestrial sources while mannitol behaves different with highest concentrations from mixed environment.

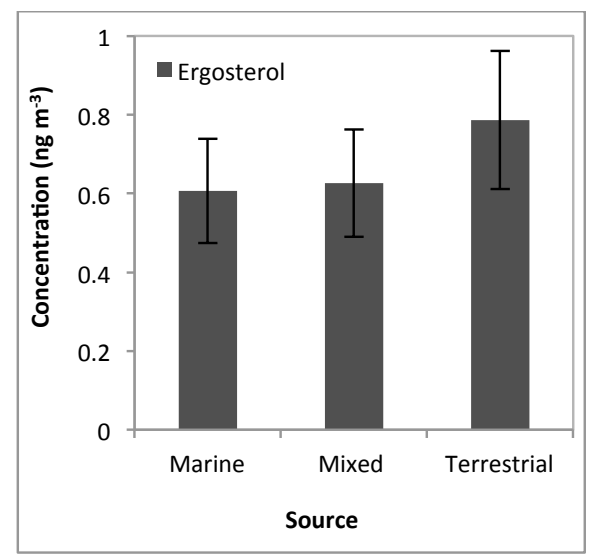

Fig. 10. Ergosterol concentrations according to source, broadly characterized to: marine environment, terrestrial sources, and mixed sources. Ergosterol has the highest concentrations when the samples are from terrestrial sources.

that the biomarkers origin is not from remote desert regions but is probably local, possibly from the southern plain area, a region with ample agriculture and vegetation. These conclusions partially contradict the conclusion of Schlesinger et al. in which higher than average concentrations of fungi were found during dust storms (Schlesinger et al., 2006). However, they agree with the conclusions of Lee et al. who did not find a distinct correlation between ergosterol and $\mathrm{Ca}^{2+}$ levels (Lee et al., 2007).

A negative or negligible correlation can be seen between $\mathrm{SO}_{4}^{2-}, \mathrm{NH}_{4}^{+}$and $\mathrm{NO}_{3}^{-}$with all markers for the entire period

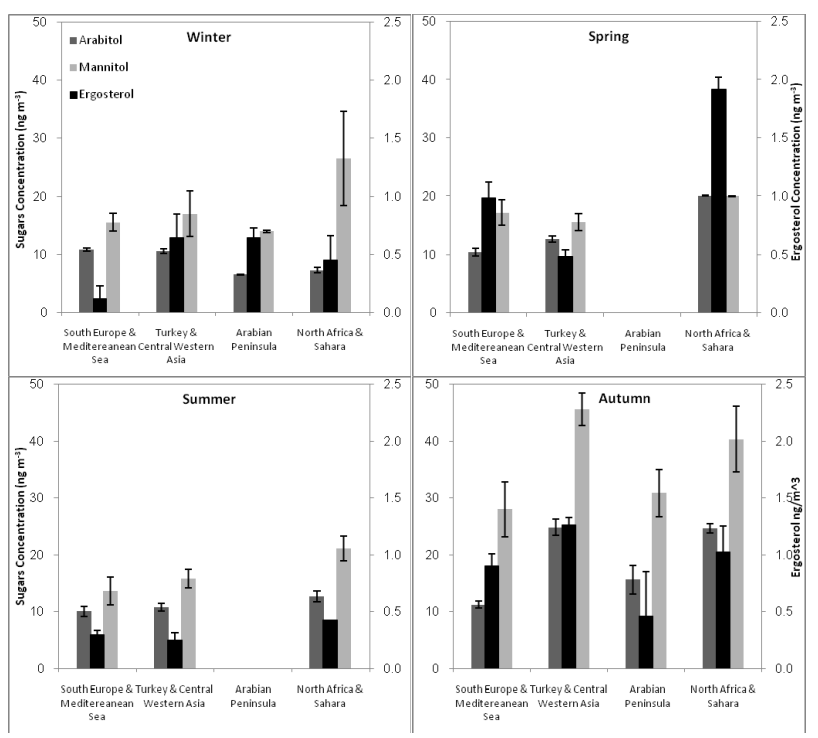

Fig. 11. Average concentrations of the biomarkers divided to the typical air mass sectors, according to seasons.

of measurements. $\mathrm{SO}_{4}^{2-}, \mathrm{NH}_{4}^{+}$and $\mathrm{NO}_{3}^{-}$are associated with aged aerosols (Lee et al., 2007) or with industrial emissions. This observation may indicate a low survival time of biogenic materials in the atmosphere, and the sensitivity of the airborne organisms to air pollution.

During the spring season, all biomarkers are correlated with all ions that are markers for marine indicating aerosols: $\mathrm{Na}^{+}, \mathrm{Cl}^{-}$and $\mathrm{Mg}^{2+}$. However, we cannot conclusively determine the source of the biomarkers. It is difficult to assess whether the prevailing western winds carried biological material from algae sources in the Mediterranean Sea or from close by terrestrial sources.

\section{Summary}

Ergosterol, mannitol and arabitol were measured during the year 2009 in order to quantify fungal distribution in the eastern Mediterranean region as well as understanding the seasonal behavior and estimate possible sources. For this purpose we established analytical methods to quantify the biomarkers. Back trajectory analysis and inorganic ions have been investigated in order to obtain source identification. We find that ergosterol, which is an established biomarker for fungi, correlates with arabitol and mannitol only during the spring and autumn months. This correlation might be related to high levels of vegetation during springs blossoms and autumn decomposition and not necessarily have a direct relation with fungi levels.

Ergosterol concentrations were found to be the highest in air masses arriving from local terrestrial sources during the autumn with an average of $0.94 \mathrm{ng} \mathrm{m}^{-3}$, while arabitol and 
mannitol have the highest levels in air masses arriving from local terrestrial and mixed sources during the autumn with an average concentration of $18.90 \mathrm{ng} \mathrm{m}^{-3}$ and $49.15 \mathrm{ng} \mathrm{m}^{-3}$, respectively.

Although ergosterol is an established biomarker for atmospheric fungal spores (Lau et al., 2006), specific conversion factors should be determined for each geographic region, fungal species and environmental conditions for further use of ergosterol as a biomarker and for establishing the actual fungi concentration. Ergosterol abundance is dependent on the fungal species present (Pasanen et al., 1999) therefore further investigation is needed in order to establish these factors for our region.

Acknowledgements. This research was partially funded by a grant from the Angel Faivovich Foundation. The authors acknowledge the help given by Ilan Levy and Noam Levin. We also gratefully acknowledge the NOAA Air Resources Laboratory (ARL) for the provision of the HYSPLIT transport and dispersion model used in this publication. Y. R. acknowledges support by the Helen and Martin Kimmel Award for Innovative Investigation.

Edited by: N. Mihalopoulos

\section{References}

Arundel, A. V., Sterling, E. M., Biggin, J. H., and Sterling, T. D.: Indirect Health-Effects of Relative-Humidity in Indoor Environments, Environ. Health Perspect., 65, 351-361, 1986.

Bauer, H., Claeys, M., Vermeylen, R., Schueller, E., Weinke, G., Berger, A., and Puxbaum, H.: Arabitol and mannitol as tracers for the quantification of airborne fungal spores, Atmos. Environ., 3(42), 588-593, 2008a.

Bauer, H., Schueller, E., Weinke, G., Berger, A., Hitzenberger, R., Marr, I. L., Puxbaum, H.: Significant contributions of fungal spores to the organic carbon and to the aerosol mass balance of the urban atmospheric aerosol, Atmos. Environ., 22(42), 55425549, 2008b.

Cheng, F. Y., Zamski, E., Guo, W. W., Pharr, D. M., and Williamson, J. D.: Salicylic acid stimulates secretion of the normally symplastic enzyme mannitol dehydrogenase: a possible defense against mannitol-secreting fungal pathogens, Planta, 6(230), 1093-1103, 2009.

Cox, C. S. and Wathes, C. M.: Bioaerosols handbook, crc press, 5-6, 1995.

Crook, B. and Sherwood-Higham, J. L.: Sampling and assay of bioaerosols in the work environment, Journal of Aerosol Science Sampling and Rapid Assay of Bioaerosols, 3(28), 417-426, 1997.

Dayan, U. and Levy, I.: The Influence of Meteorological Conditions and Atmospheric Circulation Types on $\mathrm{PM}_{10}$ and Visibility in Tel Aviv, J. Appl. Meteor., 44, 606-619, 2005.

Douwes, J., Thorne, P., Pearce, N., and Heedrik, D.: Bioaerosol Health Effects and Exposure Assessment: Progress and Prospects, Ann. Occup. Hyg., 3(47), 187-200, 2003.

Draxler, R. R. and Rolph, G. D.: HYSPLIT (HYbrid SingleParticle Lagrangian Integrated Trajectory), Model access via NOAA ARL READY Website (http://ready.arl.noaa.gov/
HYSPLIT.php), NOAA Air Resources Laboratory, Silver Spring, MD, 2010.

Elbert, W., Taylor, P. E., Andreae, M. O., and Pöschl, U.: Contribution of fungi to primary biogenic aerosols in the atmosphere: wet and dry discharged spores, carbohydrates, and inorganic ions, Atmos. Chem. Phys., 7, 4569-4588, doi:10.5194/acp-7-4569-2007, 2007.

Escudero, M., Stein, A., Draxler, R. R., Querol, X., Alastuey, A., Castillo, S., and Avila, A.: Determination of the contribution of northern Africa dust source areas to $\mathrm{PM}_{10}$ concentrations over the central Iberian Peninsula using the Hybrid Single-Particle Lagrangian Integrated Trajectory model (HYSPLIT) model, J. Geophys. Res., 111(D6), D06210, doi:10.1029/2005JD006395, 2006.

Falkovich, A. H., Ganor, E., Levin, Z., Formenti, P., and Rudich, Y.: Chemical and mineralogical analysis of individual mineral dust particles, J. Geophys. Res.-Atmos., 106(D16), 18029-18036, 2001.

Fung, F. and Hughson, W. G.: Health Effects of Indoor Fungal Bioaerosol Exposure, Appl. Occup. Environ. Hygiene, 18(7),535-544, 2003.

Gessner, M. and Schmitt, A.: Use of Solid-Phase Extraction To Determine Ergosterol Concentrations in Plant Tissue Colonized by Fungi, Appl. Environ. Microbiol., 2(62), 415-419, 1996.

Hays, M. D., Geron, C. D., Linna, K. J., Smith, N. D., and Schauer, J. J.: Speciation of gas-phase and fine particle emissions from burning of foliar fuels, Environ. Sci. Technol., 11(36), 22812295, 2002.

Hoose, C.: ATMOSPHERIC SCIENCE Biological ice formation, Nature Geosci., 6(2), 385-386, 2009.

Kurup, V. P.: Fungal allergens, Current Allergy and Asthma Reports, 5, 3, 416-423, 2003.

Kurup, V. P., Shen, H. D., and Banerjee, B.: Respiratory fungal allergy, Microbes and Infection, 9(2), 1101-1110, 2000.

Lafay-Ette, P. R., Kane, R. M., Phan, B. H., and Parrott, W. A.: Arabitol dehydrogenase as a selectable marker for plants, In Vitro Cellular \& Developmental Biology-Animal, 40, 17A-17A, 2004.

Lau, A. P. S., Lee, A. K. Y., Chan, C. K., and Fang, M.:Ergosterol as a biomarker for the quantification of the fungal biomass in atmospheric aerosols, Atmos. Environ., 40(2), 249-259, 2006.

Lee, A. K. Y., Lau, A. P. S., Chan, C. K., and Fang, M.: Source identification analysis for the airborne bacteria and fungi using a biomarker approach, Atmos. Environ., 13(41), 2831-2843, 2007.

Li, D. W. L., J.: Airborne fungi associated with ornamental plant propagation in greenhouses, Aerobiologia, 1(26), 15-28, 2010.

Loescher, W. H., Tyson, R. H., Everard, J. D., Redgwell, R. J., and Bieleski, R. L.: Mannitol Synthesis in Higher Plants: Evidence for the Role and Characterization of a NADPH-Dependent Mannose 6-Phosphate Reductase, Plant Physiol., 98(4), 1396-1402, 1992.

Madigan, M. T., Martinko, J. M., and Parker, J.: Brock Biology of Microorganisms, 8th edition, Prentice Hall, 774-775, 1997.

Mille-Lindblom, C., von Wachenfeldt, E., and Tranvik, L. J.: Ergosterol as a measure of living fungal biomass: persistence in environmental samples after fungal death, J. Microbiol. Methods, 59(2), 253-262, 2004.

Miller, J. D. and Young, J. C.: The use of ergosterol to measure exposure to fungal propagules in indoor air, American Industrial hygiene Association Journal, (58), 39-43, 1997. 
Möhler, O., DeMott, P. J., Vali, G., and Levin, Z.: Microbiology and atmospheric processes: the role of biological particles in cloud physics, Biogeosciences, 4, 1059-1071, doi:10.5194/bg-4-10592007, 2007.

Pasanen, A. L., Yli-Pietila, K., Pasanen, P., Kalliokoski, P., and Tarhanen, J.: Ergosterol content in various fungal species and biocontaminated building materials, Appl. Environ. Microbiol., 1(65), 138-142, 1999.

Pei-Chih, W., Huey-Jen, S., and Chia-Yin, L.:Characteristics of indoor and outdoor airborne fungi at suburban and urban homes in two seasons, Sci. Total Environ., 253(1-3), 111-118, 2000.

Ring, J.: Allergy and hypersensitivity - Allergies on the increase Editorial overview, Current Opinion in Immunology, 6(13), 699700, 2001.

Ruzer, L. S. and Harley, N. H.: Aerosols handbook: measurement, dosimetry, and health effects, crc press, 291-342, 2005.

Santarpia, J. L., Cunningham, D., Gilberry, J., Kim, S., Smith, E. E., Ratnesar-Shumate, S., and Quizon, J.: Transport and characterization of ambient biological aerosol near Laurel, MD, Biogeosciences Discuss., 7, 6725-6747, doi:10.5194/bgd-7-6725-2010, 2010.

Saraf, A., Larsson, L., Burge, H., and Milton, D.:Quantification of ergosterol and 3-hydroxy fatty acids in settled house dust by gas chromatography-mass spectrometry: comparison with fungal culture and determination of endotoxin by a Limulus amebocyte, Appl. Environ. Microbiol., lysate assay, 63(7), 2554-2559, 1997.
Schlesinger, P., Mamane, Y., and Grishkan, I.: Transport of microorganisms to Israel during Saharan dust events, Aerobiologia, 22, 259-273, 2006.

Shelton, B. G., Kirkland, K. H., Flanders, W. D., and Morris, G. K.: Profiles of Airborne Fungi in Buildings and Outdoor Environments in the United States, Appl. Environ. Microbiol., 68(4), 1743-1753, 2002.

Taha, M. P. M., Drew, G. H., Longhurst, P. J., Smith, R., and Pollard, S. J. T.:Bioaerosol releases from compost facilities: Evaluating passive and active source terms at a green waste facility for improved risk assessments, Atmos. Environ., 40(6), 1159-1169, 2006.

Vali, G., Kulmala, M., Wagner, P.: Ice nucleation - A review in: Nucleation and Atmospheric Aerosols, Pergamon Press, 1996.

Waisel, Y., Ganor, E., Epshtein, V., Stupp, A., and Eshel, A.: Airborne pollen, spores, and dust across the East Mediterranean Sea, Aerobiologia, 24(3), 125-131, 2008.

Womiloju, T. O., Miller, J. D., Mayer, P. M., and Brook, J. R.: Methods to determine the biological composition of particulate matter collected from outdoor airment, Atmos. Environ., 37(31), 43354344, 2003.

Zhang, T., Engling, G., Chan, Y. C., Zhang,Y. N., Zhang, Z. S., Lin, M., Sang, X. F., Li, Y. D., and Li, Y. S.: Contribution of fungal spores to particulate matter in a tropical rainforest, Environ. Res. Lett., 2(5), 024010, doi:10.1088/1748-9326/5/2/024010, 2010. 